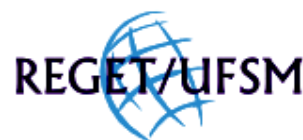

ÁVILA et all , v(11), no 11, p. 2419-2426 , JUN, 2013.

Rev. Elet. em Gestão, Educação e Tecnologia Ambiental (e-ISSN: 2236-1170)

\title{
O RETORNO DA OVINOCULTURA AO CENÁRIO PRODUTIVO DO RIO GRANDE DO SUL
}

\section{THE RETURN OF THE SHEEP INDUSTRY PRODUCTIVE SCENARIO OF RIO GRANDE DO SUL}

\author{
Viviane Schons de Ávila ${ }^{1}$, Ana Paula Burin Fruet ${ }^{2}$, Marciele Barbieri ${ }^{3}$, Nadia Helena Bianchini ${ }^{4}$, \\ Andréa Cristina Dörr ${ }^{5}$ \\ ${ }^{1}$ Universidade Federal de Santa Maria (UFSM) - Aluno do curso de Agronomia. E-mail: vivi_31589@hotmail.com \\ ${ }^{2}$ UFSM - Aluna de mestrado do Programa de Pós-graduação em Ciência e Tecnologia de Alimentos. E-mail: \\ ap_burin@hotmail.com \\ ${ }^{3}$ UFSM - Aluna do curso de Agronomia. E-mail: marcieleb@ymail.com \\ ${ }^{4}$ UFSM - Aluna do curso de Engenharia Florestal. E-mail: nadia_bianchini@hotmail.com \\ ${ }^{5}$ UFSM - Profa. Adjunto do Departamento de Ciências Econômicas: andreadoerr@yahoo.com.br
}

http://dx.doi.org/10.5902/223611708801

\begin{abstract}
RESUMO
Esta revisão tem como objetivo realizar uma análise histórica sobre a cadeia produtiva de ovinos no Rio Grande do Sul, com essa finalidade estudou-se o mercado anterior a crise laneira, do final dos anos 80, e o retorno da produtividade após a mudança no foco da produção. Os ovinos foram introduzidos no Brasil no século XVI, mas apenas no século XX a atividade gerou desenvolvimento econômico no Rio Grande do Sul, nesse período o principal produto explorado era a lã. Porém, no final da década de 80 ocorreu o início da crise do setor laneiro, causada principalmente pelo aumento dos estoques de lã da Austrália, da comercialização de tecidos sintéticos e de crises e colapsos mundiais. Atualmente é identificado o retorno da produção ovina voltada ao setor cárneo em decorrência de fatores como, o aumento do poder aquisitivo da população e adaptação a novos hábitos de consumo que levam a apreciação pela carne ovina. As tendências para esse mercado são promissoras. No entanto, existem alguns entraves ao crescimento, como a desordem do setor e a falta de padronização dos produtos. Para o Estado tornar-se grande produtor de carne ovina é preciso organizar o setor, desde a produção até os canais de distribuição.
\end{abstract}

Palavras-chave: carne ovina, crise da lã, lã, ovinos

\begin{abstract}
This review aims to conduct a historical analysis of the production chain of sheep in the Rio Grande do Sul, for this purpose we studied the market before the crisis laneira, the late 80s, and the return of productivity after the change in the focus of production. The sheep were introduced in Brazil in the sixteenth century, but only in the twentieth century the activity generated economic development in Rio Grande do Sul, in this period the main product was exploited wool. However, in the late 80 s was the beginning of the crisis in the sector laneiro, mainly caused by an increase in inventories of wool from Australia, the marketing of synthetic fabrics and global crises and collapses. Currently identified is the return of the sheep production industry dedicated to meat eating as a result of factors such as the increased purchasing power of the population and adapt to new consumer habits that lead to appreciation for sheep meat. The trends for this market are promising. However, there are some barriers to growth, as the disorder of the sector and the lack of standardization of products. For the state to become major producer of sheep meat is necessary to organize the sector, from production to distribution channels.
\end{abstract}

Keywords: sheep meat, wool, wool crisis, sheep 


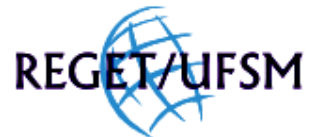

ÁVILA et all , v(11), no 11, p. 2419-2426, JUN, 2013.

Rev. Elet. em Gestão, Educação e Tecnologia Ambiental (e-ISSN: 2236-1170)

\section{INTRODUÇÃO}

Os ovinos foram introduzidos no Brasil durante o século XVI (PAIVA, 2005; MCMANUS, 2010) e nesse período explorou-se a produção laneira da espécie. No entanto, foi apenas no século $X X$ que a atividade evoluiu e gerou desenvolvimento econômico principalmente para o estado Rio Grande do Sul (VIANA, 2007).

Ao final da década de 80 ocorreu a crise da lã, a qual foi causada pelo aumento dos estoques de lã da Austrália, da comercialização de tecidos sintéticos e de uma série de crises e colapsos mundiais que ocorreram nesse período. Como conseqüência desses acontecimentos, o número de ovinos criados no Rio Grande do Sul diminuiu bruscamente (NOCCHI, 2001; VIANA, 2008b).

O cenário da ovinocultura foi alterado, pois atualmente, a carne tornou-se o principal produto da criação ovina no Rio Grande do Sul, o qual apresenta um rebanho ovino caracterizado por, aproximadamente, quatro milhões de animais (IBGE, 2010). No entanto, percebe-se a necessidade de organização da cadeia e aumento de produtividade, pois o Brasil apresentou pequena participação na produção mundial da carne ovina, 0,95\%, em 2010 (FAO, 2011).

Apesar dos ovinos serem introduzidos juntamente com outras espécies no Brasil, é observado que o número de ovinos criados não aumentou na mesma proporção de outros animais de produção (MCMANUS, 2010). Dessa forma, estudos que abrangem a evolução da cadeia e procura evidenciar possíveis entraves da produção pode colaborar com o fortalecimento da ovinocultura do Rio Grande do Sul.

O objetivo desta revisão é realizar uma análise histórica sobre a cadeia ovina no Rio Grande do Sul, com intuito de identificar o comportamento do mercado anterior a crise laneira e o retorno da produtividade nos últimos anos, após a mudança no foco da produção, assim como as implicações da crise e o mercado atual para a produção ovina.

\section{HISTÓRICO DA OVINOCULTURA}

A partir de 1556 é descrita a presença de espécies ovinas no Brasil (NUNES VIEIRA, 1967). Contudo, esta espécie não teve capacidade de se adaptar aos estados do norte devido ao clima desfavorável.

No Estado do Rio Grande do Sul o estabelecimento da ovinocultura como atividade econômica ocorreu no início do século XX com a valorização da lã no mercado internacional. Nessa época, a lã era o principal produto da ovinocultura e esse mercado estava em expansão mundialmente (VIANA \& SILVEIRA, 2009).

A ovinocultura gaúcha chegou ao apogeu durante a década de 80 , sendo considerada a segunda atividade, em nível de importância. Segundo Figueiró (1975), a maior densidade e quantidade de ovinos encontravam-se nos municípios da região Sul do Estado, mais precisamente na região da Campanha. De acordo com Nocchi (2001), nesse período, a lã atingiu o preço de US\$ $3,83 / \mathrm{kg}$ no mercado internacional durante a safra 1988/1989, preço jamais alcançado novamente, quando o rebanho gaúcho chegou a 13,5 milhões de ovinos. Os rebanhos aumentaram, assim como a necessidade de mão-de-obra, gerando mais empregos nas fazendas e maior retorno do 


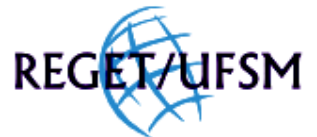

ÁVILA et all , v(11), no 11, p. 2419-2426, JUN, 2013.

Rev. Elet. em Gestão, Educação e Tecnologia Ambiental (e-ISSN: 2236-1170)

investimento aos proprietários. O volume de lã produzido no Rio Grande do Sul chegava a 36 milhões de quilogramas por ano.

Como o foco da atividade era a produção de lã, o sistema produtivo se desenvolvia com o intuito de maximizar a produção através da utilização de raças específicas para esse propósito. Portanto, o rebanho ovino gaúcho foi formado, principalmente, pelas raças Merino Australiano e Ideal, as quais são especializadas na produção de lã, e também pela raça Corriedale de duplo propósito, carne e lã, apesar da carne ovina não ter relevância nessa época (SILVEIRA, 2001). De acordo com Viana \& Silveira (2009), a carne ovina era considerada um produto secundário e não tinha importância econômica, sendo utilizada apenas para consumo dos estabelecimentos rurais.

Em seu estudo, Nocchi (2001) relata que comercialmente existia uma rede de cooperativas de lã, que recebiam, classificavam e comercializavam a lã, tanto no mercado nacional quanto internacional, competindo em nível mundial com outras economias laneiras. Essas cooperativas de lãs surgiram na década de $40 \mathrm{com}$ o apoio do governo, devido às grandes distâncias entre as fazendas e a precariedade dos transportes na época (ALVEZ RUIZ, 1982).

\section{CRISE DA LÃ}

No final da década de 80, iniciou-se uma grande crise na ovinocultura. Segundo Viana (2008b), entre os motivos que culminaram a crise está o grande estoque de lã da Austrália, principal produtor mundial, que criou um mecanismo de proteção comercial baseado em grandes compras e vendas de lã com o intuito de regular o preço. Porém, uma decisão única de desafiar os compradores a pagarem preços mais altos pela lã fez com que os consumidores contestassem e deixassem de comprar. Com isso, a Austrália estocou o produto a espera de uma reação do mercado, fato que não aconteceu. Os altos preços contaminaram outros centros produtores de lã do mundo e os consumidores deslocaram-se para o consumo de confecções de algodão e fibras sintéticas, instalando-se assim a crise no mundo inteiro (NOCCHI, 2001).

Nesse período também ocorreu o avanço tecnológico do setor têxtil, o que contribuiu para que fibra sintética ganhasse espaço no mercado, com preços altamente competitivos se comparados aos da lã (SILVEIRA, 2005).

Além disso, alguns acontecimentos ao longo da década de 90 também foram relevantes para esta crise. Citam-se o colapso na União Soviética (URSS), as crises da Europa Ocidental e Japão e a crise econômica na China e Ásia. Estes episódios colaboraram para a diminuição da demanda internacional de lã, o que justifica em partes, o aumento dos estoques na Austrália (NOCCHI, 2001).

O Rio Grande do Sul, que tinha grande importância na produção de lã, foi muito prejudicado com a crise (SANTOS et al., 2009). As exportações de lã adquiriram menos representatividade, as cooperativas responsáveis pelo recebimento, armazenamento e comercialização da lã foram desaparecendo, e assim houve a retirada do crédito subsidiado à ovinocultura (NOCCHI, 2001).

A crise provocou uma evidente diminuição dos rebanhos ovinos no Rio Grande do Sul, além de queda no preço da lã que chegou a US\$1,52/kg (FAOSTAT, 2011). Segundo Couto (2004), os produtores que abandonaram a ovinocultura buscaram, ou ainda buscam a migração para 


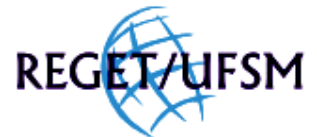

ÁVILA et all , v(11), no 11, p. 2419-2426, JUN, 2013.

Rev. Elet. em Gestão, Educação e Tecnologia Ambiental (e-ISSN: 2236-1170)

outras atividades, como a agricultura. Enquanto outros, que não querem abandonar a atividade, estão reestruturando seus rebanhos, passando a trabalhar com raças de dupla aptidão (carne e lã) e com raças específicas para a produção de carne.

O Rio Grande do Sul ainda é produtor de lã, porém, em escala menor se comparado a época anterior a crise. Segundo dados da Fecolã (OVINOS..., 2004), a lã gaúcha representa 91\% de toda produção brasileira, sendo destinada principalmente à indústria nacional de vestuário e também às indústrias de tapeçaria e artesanato.

\section{RETORNO DA OVINOCULTURA}

No início da crise muitos produtores gaúchos desfizeram-se das raças laneiras e priorizaram aquelas de dupla aptidão, como a Corriedale, na tentativa de aguardar o retorno da produção de lã ou mudar totalmente para a produção de carne ovina (NOCCHI, 2001). Portanto, com o forte agravamento da crise, os produtores que não abandonaram a atividade, passaram a importar reprodutores de raças específicas para carne, como Hampshire Down, Suffolk, lle de France e Texel (SILVEIRA, 2001). Apesar de a carne ovina ser considerada de baixa qualidade no período em que o principal produto era a lã percebeu-se uma mudança no foco da ovinocultura para a produção de carne (SILVEIRA, 2005).

Mesmo com a alteração do produto final da atividade, os rebanhos reduziram-se drasticamente, mas a atividade não desapareceu por completo (VIANA, 2008a). A ovinocultura passou a se expandir por outras regiões brasileiras além da região Sul, principalmente na região Nordeste, a qual apresenta atualmente o maior rebanho efetivo do Brasil (LARA et al., 2009). Na região Nordeste, devido ao clima semi-árido, houve a introdução de raças deslanadas, como Morada Nova e Santa Inês, assim, a ovinocultura voltou a ser uma atividade rentável (SANTOS et al., 2009).

Atualmente, as tendências para o mercado ovino são promissoras, pois, de acordo com Lara et al. (2009) as pessoas estão se adaptando aos novos hábitos de consumo e inclusive com maior apreciação pela carne ovina, o que favorece a demanda deste e indica um potencial produto substituto a outras carnes no mercado brasileiro. Segundo Santos et al. (2009) com o aumento do poder aquisitivo da população e o incremento do abate de animais precoces, surge um novo mercado para a ovinocultura. Carvalho (2004) relata que as regiões onde as pessoas apresentam maior poder aquisitivo requerem uma demanda crescente de carne ovina. Além disso, muitos consumidores já sabem qual a carne que desejam ingerir e recorrem as suas marcas prediletas.

O aumento do consumo da carne ovina pode ser visualizado na Figura 1 elaborado por Souza (2008), o qual afirma que tanto a produção quanto o consumo de carne ovina foram crescentes nos últimos anos, sendo que no ano de 2006, as duas variáveis representaram, respectivamente, 117 mil toneladas e 124,1 mil toneladas. 
Rev. Elet. em Gestão, Educação e Tecnologia Ambiental (e-ISSN: 2236-1170)

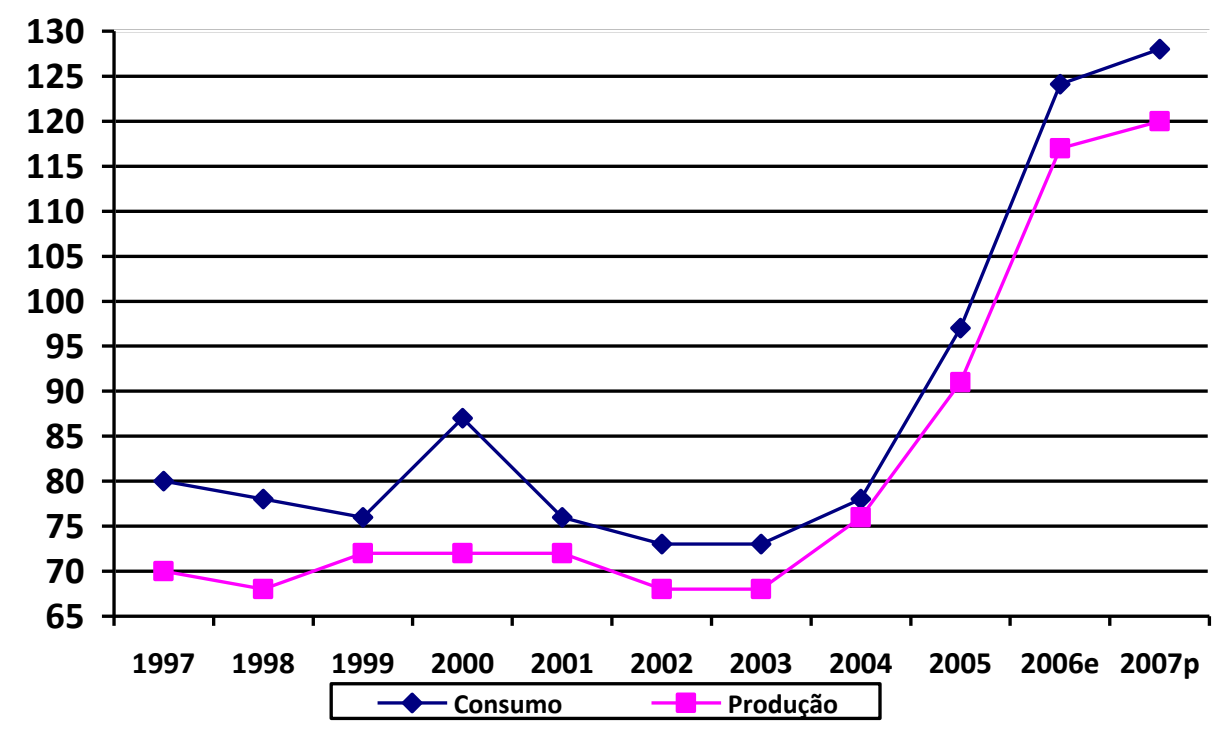

Figura 1. Produção e consumo de carne ovina no mercado brasileiro, em mil toneladas. e-estimativa; $p$-projeção.

Fonte: FAO/MAPA/MDIC, elaborado por Souza (2008).

Apesar da evolução, o rebanho ovino das regiões tradicionais de criação é insuficiente para suprir a demanda brasileira cuja situação abre espaço para a carne importada (SORIO, 2010). Parte da demanda interna é suprida com importações com destaque ao Uruguai, responsável por $60 \%$ da carne consumida no Brasil. Essa transação é favorecida pela valorização cambial existente no Brasil, o que proporciona preços mais competitivos ao Uruguai. Além disso, a carne uruguaia é rotulada como carne de qualidade superior e as importações acabam reprimindo os preços pagos ao produtor gaúcho (VIANA, 2008a).

Mesmo com a crescente demanda de carne ovina, o consumo per capita do brasileiro gira em torno de $0,7 \mathrm{~kg}$ por ano (CPT, 2010), muito inferior a outros países, como a Nova Zelândia que apresenta um consumo per capita anual de 42,2kg. Exceto no Rio Grande do Sul, a carne ovina é vista como carne de natureza exótica, tendo mais aceitação em ocasiões diferenciadas, principalmente em restaurantes, hotéis e festas, o que torna o produto mais caro (CARVALHO, 2004). Dessa forma, a carne ovina compete com outras carnes, como frango e gado que, geralmente, são mais baratas (LARA et al., 2009).

Silveira (2001) ressalta que o atual mercado da carne ovina não está organizado e estruturado como era o mercado da lã (PADILHA et al., 2008). Um grande problema desse setor é a informalidade do abate, pois, grande parte da carne ovina é proveniente do comércio clandestino e, além disso, não há padronização do produto (ALENCAR \& ROSA, 2006). Estima-se que no mínimo $90 \%$ da carne ovina consumida no país sejam de origem clandestina, com grande presença do autoconsumo (SOUZA, 2008).

Mesmo assim, o Rio Grande do Sul permanece em destaque na ovinocultura, sendo responsável por $68 \%$ da produção brasileira de carne ovina. Atualmente, conta com um rebanho de, aproximadamente, quatro milhões de ovinos (IBGE, 2010), sendo que os municípios da região da Campanha destacam-se com os maiores rebanhos, conforme já ocorria nas décadas de 70 e 80, 


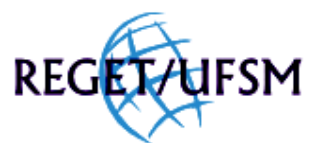

ÁVILA et all , v(11), no 11, p. 2419-2426, JUN, 2013.

Rev. Elet. em Gestão, Educação e Tecnologia Ambiental (e-ISSN: 2236-1170)

representando $69 \%$ de todo rebanho ovino do Estado (SANTOS et al., 2009). Porém, mesmo sendo um mercado promissor, a maioria dos produtores associam a criação de ovinos com bovinos e não relatam a ovinocultura como atividade principal (PADILHA et al., 2008).

\section{CONCLUSÕES}

O Brasil, com destaque ao estado do Rio Grande do Sul, participa do crescente mercado internacional de carne ovina, principalmente como importador. O que demonstra a existência de um mercado interno aquecido e oportunidades para os produtores gaúchos investirem na cadeia produtiva de ovinos.

Diante das dificuldades que a ovinocultura enfrenta, conclui-se que são necessários esforços a fim de incentivar a produção de carne ovina e organizar a cadeia produtiva. Existe espaço para melhorias nesse setor, sobretudo no que se refere à obtenção de maior volume de carne produzida.

\section{AGRADECIMENTO}

Os autores agradecem ao Governo Federal pelo financiado desta pesquisa através do MC/SID e da SGPR/SNJ Edital 01/2011.

\section{REFEÊNCIAS BIBLIOGRÁFICAS}

ALENCAR, L.; ROSA, F. R. T. Ovinos: panorama e mercado. Revista O Berro. v. 96, 2006. Disponível em: <http://www.zebus.com.br/berro/noticias ver.php?CdNotici=9>. Acesso em: 27 abr. 2012.

ALVES RUIZ, M. A. Cooperativismo - Um caminho para o desenvolvimento: Cooperativa Santanense de Lãs Ltda. (1944 - 1964). Florianópolis: UFSC, 1982. Dissertação (Mestrado em História), Universidade Federal de Santa Catarina, 1982.

CARVALHO, R. B. de. Potencialidades dos Mercados Para os Produtos Derivados de Ovinos e Caprinos. Fortaleza, 2004. Disponível em: <http://www.editora.ufla.br/Boletim/pdf/bol 53.pdf> Acesso em: 17 abr. 2012.

COUTO, F. A. A. Ovinos - Tradição e Lucratividade. Revista Rural, agosto, 2004. Disponível em: <http://www.revistarural.com.br/edicoes/2004/Artigos/rev79 ovinos.htm>. Acesso em: 17 abr. 2012.

CPT. Centro de Produções Técnicas. 2010. Disponível em: <http://www.cpt.com.br/artigos/ovinos-deslanadosexcelente-opcao-para-ovinocultores-brasileiros>. Acesso em: 10 jan. 2012.

FAOSTAT. FAO Statistics Division, 2011. Disponível em: <http://faostat.fao.org/site/573/DesktopDefault.aspx?PagelD=573\#ancor>. Acesso em: 05 fev. 2012.

FIGUEIRÓ, C. M. W. Ovinocultura no Rio Grande do Sul. Secretaria da Agricultura, Porto Alegre, RS (Brasil). Supervisão da Produção Animal. 1975. 45 p. 


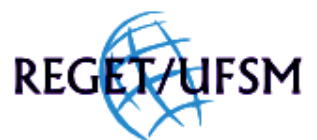

ÁVILA et all , v(11), no 11, p. 2419-2426, JUN, 2013.

Rev. Elet. em Gestão, Educação e Tecnologia Ambiental (e-ISSN: 2236-1170)

IBGE. Pesquisa Pecuária Municipal. 2010. Disponível em:

<http://www.sidra.ibge.gov.br/bda/tabela/listabl1.asp?c=73\&n=0\&u=0\&z=p\&o=27\&i=P>. Acesso em: 05 fev. 2012.

LARA, V. et al. O mercado nacional da ovinocultura. Associação Brasileira de Zootecnistas, 2009. Disponível em: $<$ http://www.google.com.br/url?sa=t\&rct=j\&q=0\%20mercado\%20nacional\%20da\%20ovinocultura\%20vivian\%20lara\% 2C\&source=web\&cd=1\&ved=0CCQQFjAA\&url=http\%3A\%2F\%2Fwww.abz.org.br\%2Ffiles.php\%3Ffile\%3Ddocumentos\% 2FVivian work ovino 278887423.pdf\&ei=waqNT6eiN4aFgwfH3f2qDg\&usg=AFQjCNGpQOGWG4Dsb8FT2sGwg7allTa6w>. Acesso em: 17 abr. 2012.

MCMANUS, C.; PAIVA, S. R.; ARAÚJO, R. O. de. Genetics and breeding of sheep in Brazil. Revista Brasileira de Zootecnia, v. 39, p. 236-246, 2010 (supl. especial).

NOCCHI, E. D. G. Os efeitos da crise da lã no mercado internacional e os impactos sócio-econômicos no município de Santana do Livramento, RS, Brasil. Rosário: UNR, 2001. Dissertação (Mestrado em integração e cooperação internacional), Universidad Nacional de Rosario, 2001.

NUNES VIEIRA, G. V. Criação de Ovinos. São Paulo: Melhoramentos, 3. ed., 1967. 25p.

OVINOS - Tradição e Lucratividade. Revista Rural, n. 79, ago. 2004. Disponível em:

<http://www.revistarural.com.br/edicoes/2004/Artigos/rev79_ovinos.htm>. Acesso em: 20 ago. 2012.

PADILHA, A. C. M. et al. A Reestruturação do agronegócio da ovinocultura no Estado do Rio Grande do Sul: uma análise na perspectiva da competitividade. Revista de Estudos de Administração, v. 8, n. 16, p. 145-164, 2008.

PAIVA, S. R. et al. Origin of the main locally adapted sheep breeds of Brazil: a RFLP-PCR molecular analysis. Archivos de Zootecnia, v. 54, p. 395-399, 2005.

SANTOS, D. V.; AZAMBUJA, R. M.; VIDOR, A. C. Dados populacionais do rebanho ovino gaúcho. Departamento de Produção Animal (DPA) da Secretaria da Agricultura, Pecuária, Pesca e Agronegócio (SEAPPA). Porto Alegre - RS, 2009. Disponível em:

<http://www.saa.rs.gov.br/uploads/1294316729Dados populacionais do rebanho ovino gaucho.pdf>. Acesso em: 17 abr. 2012.

SILVEIRA, E. O. da. Comportamento Ingestivo e Produção de Cordeiros Em Pastagem de Azevém Anual (Lolium multiflorum Lam.) Manejada em Diferentes Alturas. Porto Alegre: UFRGS, 2001. Dissertação (Mestrado em Zootecnia), Universidade Federal do Rio Grande do Sul, 2001.

SILVEIRA, H. S. A Coordenação na Cadeia Produtiva da Ovinocultura como instrumento para o Desenvolvimento Regional: $O$ caso da Iniciativa Local do Cordeiro Herval premium. Porto Alegre: UFRGS, 2005. Dissertação (Mestrado em Agronegócios). Universidade Federal do Rio Grande do Sul, 2005.

SORIO, A. Carne ovina e caprina: produção e consumo no Brasil e nas Américas. FarmPoint: O ponto de encontro da cadeia produtiva de ovinos e caprinos. 2010. Disponível em: <http://www.farmpoint.com.br/cadeiaprodutiva/conjuntura-de-mercado/carne-ovina-e-caprina-producao-e-consumo-no-brasil-e-nas-americas62919n.aspx>. Acesso em: 27 abr. 2012. 
REGETfUSM ÁVILA et all , v(11), no 11, p. 2419-2426, JUN, 2013.

Rev. Elet. em Gestão, Educação e Tecnologia Ambiental (e-ISSN: 2236-1170)

SOUZA, D. A. Mercado doméstico da carne ovina: qual a situação e para onde estamos indo? FarmPoint: $O$ ponto de encontro da cadeia produtiva de ovinos e caprinos. 2010. Disponível em:

< http://www.farmpoint.com.br/cadeia-produtiva/conjuntura-de-mercado/mercado-domestico-da-carne-ovina-quala-situacao-e-para-onde-estamos-indo-42406n.aspx>. Acesso em: 27 abr. 2012.

VIANA, J. G. A.; SOUZA, R. S. de. Price tendency of sheep products in the state of Rio Grande do Sul from 1973 to 2005. Ciência e Agrotecnologia, v. 31, n. 1, p. 191-199, 2007.

VIANA, J. G. A. Panorama Geral da Ovinocultura no Mundo e no Brasil. Revista Ovinos, v. 4, n.12, Porto Alegre, $2008 a$.

VIANA, J. G. A. Governança da cadeia produtiva da ovinocultura no Rio Grande do Sul: estudo de caso à luz dos custos de transação e produção. Santa Maria: UFSM, 2008. Dissertação (Mestrado em Extensão Rural), Faculdade de Zootecnia, Universidade Federal de Santa Maria, 2008b.

VIANA, J. G. A.; SILVEIRA, V. C. P. Análise econômica da ovinocultura: estudo de caso na Metade Sul do Rio Grande do Sul, Brasil. Revista Ciência Rural, v. 39, n. 4, p. 1187-1192, 2009. 